\title{
Multistage Expansion Planning of Integrated Biogas and Electric Power Delivery System Considering the Regional Availability of Biomass
}

Shahidehpour, Mohammad; Li, Canbing; Yang, Hanyu; Zhang, Cong; Zhou, Bin; Wu, Qiuwei; Zhou, Long

Published in:

IEEE Transactions on Sustainable Energy

Link to article, DOI:

10.1109/TSTE.2020.3025831

Publication date:

2021

Document Version

Peer reviewed version

Link back to DTU Orbit

Citation (APA):

Shahidehpour, M., Li, C., Yang, H., Zhang, C., Zhou, B., Wu, Q., \& Zhou, L. (2021). Multistage Expansion Planning of Integrated Biogas and Electric Power Delivery System Considering the Regional Availability of Biomass. IEEE Transactions on Sustainable Energy, 12(2), 920 - 930.

https://doi.org/10.1109/TSTE.2020.3025831

\section{General rights}

Copyright and moral rights for the publications made accessible in the public portal are retained by the authors and/or other copyright owners and it is a condition of accessing publications that users recognise and abide by the legal requirements associated with these rights.

- Users may download and print one copy of any publication from the public portal for the purpose of private study or research.

- You may not further distribute the material or use it for any profit-making activity or commercial gain

- You may freely distribute the URL identifying the publication in the public portal 


\title{
Multistage Expansion Planning of Integrated Biogas and Electric Power Delivery System Considering the Regional Availability of Biomass
}

\author{
Hanyu Yang, Student Member, IEEE, Canbing Li, Senior Member, IEEE, Mohammad Shahidehpour, \\ Fellow, IEEE, Cong Zhang, Member, IEEE, Bin Zhou, Senior Member, IEEE, Qiuwei Wu, Senior \\ Member, IEEE, Long Zhou
}

\begin{abstract}
Centralized biogas plant (CBP) provides an attractive solution to the energy supply for district heating, electric loads, and residential cooking in remote areas via a local biogas delivery network. To overcome the challenges of biomass availability for CBPs, an integrated expansion planning model is proposed in this paper. The model makes investment decisions on the sequential planning of integrated electric power distribution and biogas delivery networks and uses the constrained biomass transportation network to optimally determine CBP locations in the integrated network. The proposed approach also considers the biomass availability and the cost of biomass supply in the integrated model. The proposed multistage stochastic planning problem makes investment decisions considering the gradual realization of uncertainties as loads grow and biomass is made available. The polyhedral approximation method is applied to convert the proposed mixed-integer second-order cone programming (MISOCP) problem to a mixed-integer linear programming (MILP) problem for making the problem more tractable for large-scale cases. The effectiveness of the proposed integrated model is validated using an 8-node and a 24-node test system.
\end{abstract}

Index Terms-Biomass energy, expansion planning of integrated energy system, electric power distribution, stochastic programming.

\section{NOMENCLATURE}

\section{A. Indices and Sets:}

$g, l, p, j, a$

Indices of biogas-fired generators, substations, conductor types

$t, b, w$

Indices of planning stages, load blocks, scenarios

$n, n_{s}, n_{r}$ Indices of nodes, sending nodes and receiving nodes

$\Omega_{a}, \Omega_{a}^{R L}$ conductor type of replaceable lines.

This work is supported by the National Natural Science Foundation of China (51722701). C. Li is with the School of Electronic Information and Electrical Engineering, Shanghai Jiao Tong University, Shanghai 200240, China (E-mail: licanbing@sjtu.edu.cn). H. Yang, C. Zhang and B. Zhou are with the College of Electrical and Information Engineering, Hunan University, Changsha 410082, China, and also with the Hunan Key Laboratory of Intelligent Information Analysis Integrated Optimization for Energy Internet, Hunan University, Changsha 410082, China (E-mail: sullianyeung@hotmail.com, zcong@hnu.edu.cn, binzhou@hnu.edu.cn). M. Shahidehpour is with the Electrical and Computer Engineering Department, Illinois Institute of Technology in Chicago, IL 60616. USA. (E-mail: ms@iit.edu). Q. Wu is with the Center for Electric Power and Energy (CEE), Department of Electrical Engineering, Technical University of Denmark (DTU), Kgs. Lyngby 2800, Denmark. (E-mail: qw@elektro.dtu.dk). L. Zhou is with the Power Research Institute of China Southern Power Grid Company Limited, Guangzhou 528000, China. (E-mail: zhoulong20021013@163.com).

$\Omega_{n}$

NAL, NRL, NIL, $N C L$

$N N, N B$

$N P, N G, N S$

\section{B. Parameters:}

$a^{I L}, a^{R L}$

$P_{w}$

$d$

$R E$

$\lambda^{C B P}$

$P D_{n}, Q D_{n}$

$P E_{g}^{\max / \min }, Q E_{g}^{\max / \min }$

$P E_{j}^{\max / \min }, Q E_{j}^{\max / \min }$

$\alpha, \beta$

$G D_{n}$

$B D_{n}$

$V_{n}^{\max }, V_{n}^{\min }$

$R^{a}, X^{a}, Z^{a}$

$\eta_{\text {bio }}$

$I^{a, \max }$

K

$D T$

$G F^{\max / \min }$

$G P^{\max / \min }$

GIC $_{g}$, PIC $_{p}, L I C_{l}^{a}$

$M$

$B I C, B O C$

FOC
Sets of generators, substation, lines and pipes collecting to node $n$

Sets of all lines, existing replaceable lines, existing fixed lines, and candidate lines

Set of all nodes, and set of candidate nodes where CBP is installed

Sets of candidate pipelines, biogasfired generators, and existing substation.

Conductor type of irreplaceable and replaceable lines

Scenario probability

Degrading factor

System spinning reserve capacity

Capacity of candidate CBP

Expected active and reactive power demands at node $n$

Upper/Lower limits for active and reactive power of biogas-fired generator $g$

Upper/Lower limits for active and reactive power of substation $j$

Conversion coefficients of biogas-fired generators

Expected biogas demand at node $n$

Expected annual biomass availability at node $n$

Upper and lower limits of square magnitude of nodal pressure

Resistance, reactance, and impedance of conductor type $a$

Conversion coefficient for CBP

Maximum square magnitude of current flow in conductor type $a$

Weymouth constant

Load duration

Upper/Lower limits of biogas flow

Upper/Lower limits of nodal pressure

Investment costs of generator $g$, pipeline $p$, line $l$ of conductor type $a$

Sufficiently large number

Investment and operation prices of CBP

Fixed transportation price 


\begin{tabular}{|c|c|}
\hline$V C$ & Distance-variable price \\
\hline$N_{N N}^{t}, N_{j}$ & $\begin{array}{l}\text { Numbers of demand nodes at stage } t \text {, } \\
\text { substation nodes }\end{array}$ \\
\hline \multicolumn{2}{|c|}{ C. Variables: } \\
\hline$x_{n}$ & Investment status of CBP at node $n$ \\
\hline$x_{g t}, x_{p t}, x_{l t}^{a}$ & $\begin{array}{l}\text { Investment status of biogas-fired } \\
\text { generator } g \text {, pipeline } p \text {, line } l \text { of } \\
\text { conductor type } a \text { at stage } t\end{array}$ \\
\hline$y_{n_{s} n_{r}}$ & $\begin{array}{l}\text { Binary utilization variable of biomass } \\
\text { transportation route from } n_{s} \text { to } n_{r}\end{array}$ \\
\hline$I C, O C_{w}$ & $\begin{array}{l}\text { Investment and operation costs in } \\
\text { scenario } w\end{array}$ \\
\hline$F C$ & Distance-fixed cost \\
\hline$B T C$ & Biomass transportation cost \\
\hline$P E_{g}, Q E_{g}$ & $\begin{array}{l}\text { Active and reactive power generated } \\
\text { from biogas-fired generator } g\end{array}$ \\
\hline$P G_{g}$ & Biogas consumed by generator $g$ \\
\hline$V_{n}$ & Square magnitude of nodal voltage \\
\hline$B S_{n_{s} n_{r}}$ & Shipment from node $n_{s}$ to node $n_{r}$ \\
\hline$B G$ & Hourly biogas yield of CBP \\
\hline$I$ & Square magnitude of current flow \\
\hline$I^{a}$ & $\begin{array}{l}\text { Square magnitude of current flow of } \\
\text { conductor type } a\end{array}$ \\
\hline$P F^{a}, Q F^{a}$ & $\begin{array}{l}\text { Active and reactive power flows of } \\
\text { conductor type } a\end{array}$ \\
\hline$P S_{j}, Q S_{j}$ & $\begin{array}{l}\text { Active and reactive power generated } \\
\text { from substation } j\end{array}$ \\
\hline$P F, Q F$ & Active and reactive power flows \\
\hline$S F, S F^{a}$ & $\begin{array}{l}\text { Apparent power flow, Apparent power } \\
\text { flow of conductor type } a\end{array}$ \\
\hline$G F$ & Biogas flow \\
\hline$G P_{n}$ & Nodal pressure \\
\hline$\xi^{+}, \xi^{-}$ & $\begin{array}{l}\text { Binary variables for biogas flow } \\
\text { direction }\end{array}$ \\
\hline$\theta$ & Auxiliary variable for model relaxation \\
\hline
\end{tabular}

\section{INTRODUCTION}

$\mathrm{T}$ HE natural gas network is not extended to many remote regions of the world because of the comparatively expensive cost of the natural gas network infrastructure. A viable and affordable substitution for natural gas is biogas in places where the abundant biomass availability creates an opportunity for utilizing biogas as a regional clean energy access. Correspondingly, a centralized biogas plant (CBP), which collects locally-sourced animal manure or organic waste for anaerobic treatment, can supply biogas loads in remote communities. Biogas provides an attractive energy solution for district heating, electric loads, and residential cooking via a local biogas transportation network for delivery. Also, the biogas produced in CBP can be delivered via pipelines to power plants in the electric power network. Therefore, biogas and electricity form an integrated energy system for supplying multiple local loads.

In principle, the coordinated planning of electricity and natural gas system is similar to that of electricity and biogas system. So, we first review some of the analogous studies in the former system. The study in [1] proposed a two-stage scenario- based stochastic planning model for the integrated energy system. In [2], a chance-constrained programming model included storage and compressors in the integrated planning of electricity and natural gas. A multi-stage stochastic planning model presented in [3] considered investment decisions sequentially in which uncertainties were revealed in each period. A robust integrated planning of power and natural gas system which included the N-1 contingency criterion was proposed in [4]. The study in [5] proposed an integrated electric power and natural gas system planning model for enhancing the power grid resilience in extreme conditions. A low carbon expansion planning method for power and natural gas system was presented in [6] considering market interactions among various participants. In [7], A multi-objective expansion planning model is developed to simultaneously minimize the investment cost and production cost of power and natural gas system considering $N^{-1}$ electricity network security criterion. Compared with numerical natural gas constrained electric power system studies at the transmission level, fewer studies have paid attention to that at the distribution level. In [8], a holistic approach was proposed to solve a mixed-integer nonlinear model that coordinated the planning of natural gas and electric power distribution networks which were constrained by a simplified linear alternative current (AC) power flow model with multiple infrastructural alternatives.

However, different from the natural gas supply, the biogas supply is particularly available by collecting and transporting the biomass feedstock from several communities to CBP via biomass transportation network. Thus, a tight correlation is expected between regional biomass availability and energy supply. The correlation further requires the consideration of the biomass transportation network in the coordinated planning of power and biogas delivery systems where the natural gas supply and delivery network are very limited.

The integration of biomass transportation network has been discussed in previous studies where the CBP-based biomass supply chain was optimized for identifying the optimal path from bioenergy to biofuel. In [9], a deterministic district heating planning model was driven by the biogas generated from a wastewater treatment plant. A deterministic mixed-integer linear programming (MILP) model was proposed in [10] concerning the biomass supply chain for district heating and cooling system. In [11], a MILP based spatial optimization methodology is proposed for the integration of biomass into urban energy system for regional heat and power supplies. Other studies utilized geographic information system (GIS) to analyze available resources, plant locations, transportation logistics and costs [12],[13]. Such models for coupled networks are usually formulated as route optimization problems which do not consider uncertainty or physical network constraints. These models cannot be accurately applied to practical expansion planning of coupled infrastructures.

Therefore, faced with the imbalance between energy demands and regional biomass availability, we propose an expansion planning of the integrated electric and biogas delivery networks considering regional biomass availability. The contributions are summarized as follows:

1) An integrated planning model is proposed for three coupled networks considering the detailed characteristics of electric power, biogas delivery, and biomass transportation networks. 
The proposed solution makes investment decisions on expansions of electric power and biogas delivery networks and optimally determines CBP locations using transportation constraints.

2) Given the transportation network topology and the uncertainty of regional biomass availability, a fixed charge transportation cost is incorporated to determine the optimal biomass transportation routes that will influence $\mathrm{CBP}$ locations. 3) A polyhedral approximation method is applied to convert the MISOCP problem into a tractable MILP problem. Additionally, a multistage planning model with non-anticipativity constraints is proposed where the investment decisions are made sequentially as uncertainties of demand growth and biomass availability are revealed gradually.

The remainder of this paper is organized as follows. Section II presents the modeling of the proposed integrated network. Section III presents the integrated expansion planning model. In Section IV, the polyhedral approximation and a sequential planning method dealing with uncertainty are presented. Section V presents the simulation and Section VI concludes.

\section{MODELING OF THE PROPOSED INTEGRATED NETWORK}

In Fig. 1, electric power, biogas delivery, and biomass transportation networks are coupled by the installation of CBP and biogas-fired electric generators. Given that the CBP codigests manure and other organic wastes such as industrial organic waste, source sorted household waste, and sewage sludge, the feedstock can be collected at nodes where residents also have basic energy demands. Those nodes are denoted as either demand nodes or biomass supply nodes in Fig. 1. The model of the biogas delivery network is addressed as followed.

Here, we assume there is only one local CBP as indicated in (1). The biomass transportation route between any two nodes is associated with the CBP location indicator $x_{n}$. If $x_{n}=0$, then there is no CBP at node $n_{r}$, and the biomass feedstock transported to node $n_{r}$ is equal to 0 for all nodes $n_{s}$, as indicated in (2)-(3) where $y_{t w n_{s} n_{r}}$ is the utilization variable which indicates whether or not the transportation route from node $n_{s}$ to node $n_{r}$ is used. Constraint (4) imposes the biomass availability limit at each node.

$$
\begin{gathered}
\sum_{n \in N B} x_{n}=1 \\
0 \leq B S_{t w n_{s} n_{r}} \leq M \cdot y_{t w n_{s} n_{r}} \forall t, \forall w, \forall n_{s} n_{r} \in N N \\
y_{t w n_{s} n_{r}} \leq x_{n_{r}}, \forall n_{r} \in N B, \forall t, \forall w \\
\sum_{n_{r} \in N B} B S_{t w n_{s} n_{r}} \leq B D_{t w n_{s}}, \forall n_{s} \in N N, \forall t, \forall s
\end{gathered}
$$

It should be noted that most CBPs are equipped with feedstock storage and feedstock transportation does not have to be correlated with the hourly power and biogas dispatch. Accordingly, the uncertainty of biomass availability can be estimated on an annual basis despite seasonal variations in biomass availability. Given the total biomass feedstock collected from various nodes, the total annual biogas produced by CBP in each scenario is stated by (5). The total annual biogas yield is limited by the maximum CBP capacity in (6).

$$
\sum_{n_{s} \in N N} \eta_{b i o} \cdot B S_{t w n_{s} n}=\sum_{b} D T_{b} \cdot B G_{t b w n}, \forall n \in N B, \forall t, \forall w
$$

$$
\sum_{w} \sum_{b} P_{w} \cdot D T_{b} \cdot B G_{t b s n} \leq x_{n} \cdot \lambda^{C B P}, \forall n \in N B, \forall t
$$

The hourly biogas yield is equal to the sum of the nodal biogas demand and the biogas consumption by each candidate generator in (7), regardless of network losses. Here, constraint (7) shows the coupling of electric, biomass transportation and biogas delivery networks.

$$
B G_{t b w n}=\sum_{g \in N G} P G_{t b w g}+\sum_{n \in N N} G D_{t b w n}, n \in N B, \forall t, \forall b, \forall w
$$

Once the CBP is installed at a certain node, the transportation routes that collect and transport biomass feedstock to $\mathrm{CBP}$ and the total transportation cost can be determined accordingly. Usually, the transportation cost includes a variable cost and a fixed cost. The fixed cost is independent of transportation distance, and typically includes feedstock loading and uploading costs [14], as indicated in (8). Once a transportation route is utilized $\left(y_{t w n_{s} n_{r}}=1\right)$ for realizing a biomass transportation route between two nodes, the fixed cost is applied. Therefore, in a scenario, the transportation cost between any two nodes is stated as (9).

$$
\begin{gathered}
F C_{t w n_{s} n_{r}}=B S_{t w n_{s} n_{r}} \cdot F O C, n_{r} \in N B, n_{s} \in N N, \forall t, \forall w \\
B T C_{t w n_{s} n_{r}}=B S_{t w n_{s} n_{r}} \cdot R L_{n_{s} n_{r}} \cdot V C+F C_{t w n_{s} n_{r}} \\
n_{r} \in N B, n_{s} \in N N, \forall t, \forall w
\end{gathered}
$$

where the matrix $R L_{n_{s} n_{r}}$, denoting all the shortest travel paths from a CBP candidate node to all other nodes, is calculated by the Dijkstra's shortest path algorithm [15].
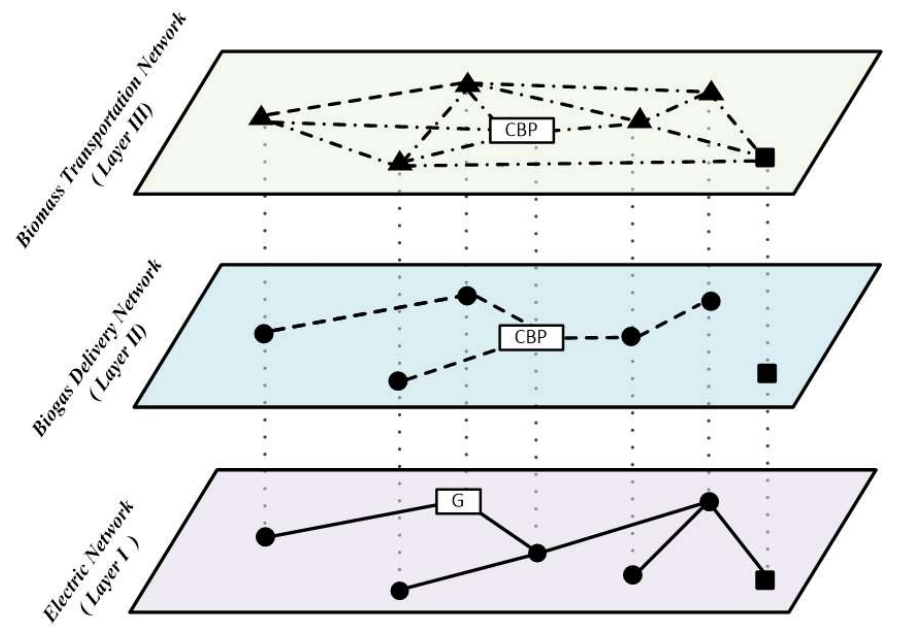

Demand node $\mathbf{D}$ Substation $\mathbf{A}$ Biomass supply node $\mathrm{G}$ Biogas-fired generator

Fig. 1. Coupling in the integrated network of electric power, biogas delivery, and biomass transportation.

\section{Formulation OF THE PROPOSED MODEL}

In this section, the objective and constraints of electric power and biogas delivery networks are presented by using an $\mathrm{AC}$ flow model, radial network structure and multiple investment alternatives. Incorporating the biomass transportation model presented in Section II, the proposed planning model is stated as a MISOCP problem.

\section{A. Objective Function}

This proposed stochastic coordinated expansion planning model will optimally locate a CBP in a rural area where the 
natural gas network is yet to be extended, while it is feasible to sequentially add or reinforce power lines and biogas pipelines. This objective is to minimize the total investment and operation costs of CBP over a planning horizon, stated as (10)-(12).

$$
\begin{gathered}
\min I C+\sum_{w} P_{w} \cdot O C_{w} \\
I C=\sum_{n \in N B} x_{n} \cdot B I C+\sum_{t} k_{t} \sum_{i \in N G}\left(x_{g t}-x_{g t-1}\right) \cdot G I C_{g} \\
+\sum_{t} k_{t} \sum_{p \in N P}\left(x_{p t}-x_{p t-1}\right) \cdot P I C_{p} \\
+\sum_{t} k_{t} \sum_{a \in \Omega_{a}} \sum_{l \in N C L}\left(x_{l t}^{a}-x_{l t-1}^{a}\right) \cdot L I C_{l}^{a} \\
+\sum_{t} k_{t} \sum_{a \in \Omega_{a}^{R L}} \sum_{l \in N R L}\left(x_{l t}^{a}-x_{l t-1}^{a}\right) \cdot L I C_{l}^{a} \\
O C_{w}=\sum_{t} k_{t} \sum_{b} D T_{b} \sum_{n \in N A L} \sum_{a \in \Omega_{a}} I_{t b w n_{s} n_{r}}^{a} \cdot R_{n_{s} n_{r}}^{a} \\
+\sum_{t} k_{t} \sum_{n_{s} \in N N} \sum_{n_{r} \in N B} B T C_{t w n_{s} n_{r}} \\
+\sum_{t} k_{t} \sum_{b} D T_{b} \sum_{n \in N B} B G_{t b w n} \cdot B O C
\end{gathered}
$$

The total investment include the initial CBP investment in the first year and annual investments on new infrastructures, e.g., biogas-fired generators, pipelines, and power lines, as represented in (11). The total annual operation cost indexed with scenarios is presented in (12), including the costs of network losses, CBP operation, and biomass transportation. The biogas-fired generators consume biogas which are represented as loads in the biogas network. Their production costs are implicitly included in the CBP production cost. Also, $k_{t}=1 /(1+d)^{t-1}$ is the coefficient of present-worth value.

\section{B. Constraints}

\section{1) Investment Constraints}

The coordinated planning model considers investments in generators, power lines and biogas pipelines, subject to (13)(19). Once a candidate generator/pipeline/line is installed or reinforced, its investment status will be fixed to 1 for the remaining years, as indicated in (13)-(16). Constraint (17) guarantees that conductor types of existing lines are fixed during the planning horizon. Constraint (18) ensures that a maximum of one construction or reinforcement is performed on each line, and each line possesses only one of candidate conductor types during the planning horizon. Constraint (19) ensures that the total capacity of installed and existing generators at the substation level can supply the forecasted peak demand and reserve.

$$
\begin{gathered}
x_{p t-1} \leq x_{p t}, \forall p \in N P, \forall t \\
x_{g t-1} \leq x_{g t}, \forall g \in N G, \forall t \\
x_{l t-1}^{a} \leq x_{l t}^{a}, \forall t, \forall l \in N C L, \forall a \in \Omega_{a} \\
x_{l t-1}^{a} \leq x_{l t}^{a}, \forall t, \forall l \in N R L, \forall a \in \Omega_{a}^{R L} \\
x_{l t-1}^{a}=x_{l t}^{a}=1, \forall t, \forall l \in N I L, a=a^{I L} \\
\sum_{a \in \Omega_{a}} x_{l t}^{a} \leq 1, \forall t, \forall l \in N A L \\
P S^{\max }+\sum_{i \in N G} x_{g t} \cdot P E_{g}^{\max } \geq \sum_{n \in N B} P D_{t b w n}+R E_{t b w}, \forall b, \forall t, \forall w
\end{gathered}
$$

\section{2) Electric Network Constraints}

Different from transmission networks where a linear DC model is generally adopted, most electric power distribution systems are represented by a tree-like radial topology, where the reactive power and nodal voltages are taken into consideration [16], [17]. Here, a convex branch flow model is adopted in (20)-(24), which is widely used in various distribution system applications [18]-[20] and its validity was presented in [21]. Constraints (20)-(21) are nodal active and reactive power flow balances. Constraint (22) calculates the voltage drop along a line. Constraints (23)-(24) relate active, reactive, and apparent power flows, and present their relations to the voltage magnitude at the sending end and the current flow magnitude along the line. Constraints (25)-(28) are employed to show that each line uses only one candidate conductor type. Constraints (29)-(34) impose upper and lower limits to nodal voltages, current flows, output power of candidate biogas-fired generators, and substations, respectively. Additionally, the network radiality is constrained by (35), which is valid without considering transfer nodes or isolated nodes where a candidate generator is located [22].

$$
\begin{aligned}
& \sum_{n_{s} \in \Omega_{n}} P F_{t b w n_{s} n}=\sum_{n_{n} \in \Omega_{n}} P F_{t b w n n_{r}}-\sum_{g \in \Omega_{n}} P E_{t b w g}+P D_{t b w n} \\
& -\sum_{j \in \Omega_{n}} P S_{t b w j}, \forall n, n_{s}, n_{r} \in N A L, \forall t, \forall b, \forall w \\
& \sum_{n_{s} \in \Omega_{n}} Q F_{t b w n_{s} n}=\sum_{n_{r} \in \Omega_{n}} Q F_{t b w n n_{r}}-\sum_{g \in \Omega_{n}} Q E_{t b w g}+Q D_{t b w n} \\
& -\sum_{j \in \Omega_{n}}^{n_{r} \in \Omega_{n}} Q S_{t b w j}, \forall n, n_{s}, n_{r} \in N A L, \forall t, \forall b, \forall w \\
& V_{t b w n_{s}}-V_{t b w n_{r}}=\sum_{a \in \Omega_{a}}\left\{2\left(R_{n_{s} n_{r}}^{a} \cdot P F_{t b w n_{s} n_{r}}^{a}+X_{n_{s} n_{r}}^{a} \cdot Q F_{t b w n_{s} n_{r}}^{a}\right)\right. \\
& \left.-\left(Z_{n_{s} n_{r}}^{a}\right)^{2} \cdot I_{t b w n_{s} n_{r}}^{a}\right\}, \forall n_{r}, n_{s} \in N A L, \forall t, \forall b, \forall w \\
& P F_{t b w n_{s} n_{r}}^{a^{2}}+Q F_{t b w n_{s} n_{r}}^{a^{2}} \leq S F_{t b w n_{s} n_{r}}^{a^{2}}, \forall n, n_{r}, n_{s} \in N A L, \forall t, \forall b, \forall w \\
& I_{t b w n_{s} n_{r}}^{a} \cdot V_{t b w n_{s}} \geq S F_{t b w n_{s} n_{r}}^{a^{2}}, \forall n_{r}, n_{s} \in N A L, \forall t, \forall b, \forall w \\
& P F_{t b w n_{s} n_{r}}=\sum_{a \in \Omega_{a}} P F_{t b w n_{s} n_{r}}^{a}, \forall n_{r}, n_{s} \in N A L, \forall t, \forall b, \forall w \\
& Q F_{t b w n_{s} n_{r}}=\sum_{a \in \Omega_{a}} Q F_{t b w n_{s} n_{r}}^{a}, \forall n_{r}, n_{s} \in N A L, \forall t, \forall b, \forall w \\
& S F_{t b w n_{s} n_{r}}=\sum_{a \in \Omega_{a}} S F_{t b w n_{s} n_{r}}^{a}, \forall n_{r}, n_{s} \in N A L, \forall t, \forall b, \forall w \\
& I_{t b w n_{s} n_{r}}=\sum_{a \in \Omega_{a}} I_{t b w n_{s} n_{r}}^{a}, \forall n_{r}, n_{s} \in N A L, \forall t, \forall b, \forall w \\
& V_{n}^{\min } \leq V_{t b w n} \leq V_{n}^{\max }, \forall n \in N N, \forall t, \forall b, \forall w \\
& I_{t b w n_{s} n_{r}}^{a} \leq x_{t n_{s} n_{r}}^{a} \cdot I^{a, \max }, \forall n_{r}, n_{s} \in N A L, \forall t, \forall b, \forall w \\
& x_{g t} \cdot P E_{g}^{\min } \leq P E_{t b w g} \leq x_{g t} \cdot P E_{g}^{\max }, \forall g \in N G, \forall t, \forall b, \forall w(3 \\
& x_{g t} \cdot Q E_{g}^{\min } \leq Q E_{t b w g} \leq x_{g t} \cdot Q E_{g}^{\max }, \forall g \in N G, \forall t, \forall b, \forall w \\
& Q S^{\min } \leq Q S_{t b w j} \leq Q S^{\max }, j \in N S, \forall t, \forall b, \forall w \\
& P S^{\min } \leq P S_{t b w j} \leq P S^{\max }, j \in N S, \forall t, \forall b, \forall w \\
& \sum_{l \in N A L} \sum_{a \in \Omega_{a}} x_{l t}^{a}=N_{N N}^{t}-1, \forall t
\end{aligned}
$$




\section{3) Biogas Delivery Network Constraints}

Since biogas has common characteristics with natural gas, the Weymouth model of the natural gas network is applied here [23]. Accordingly, the nodal biogas load balance is presented in (36). Constraint (37) indicates that biogas flow depends on the installation state of the corresponding candidate pipeline, and (38) limits the nodal pressure. As biogas flow directions are not pre-specified, a nonlinear function of biogas flow and nodal pressure is presented in (39)-(40). Constraints (41)-(43) are equivalent reformulations of (39)-(40) to remove the nonlinearity incurred by a sign function. The nonconvexity of (41) can be further relaxed as a second-order cone form in (44)(48) using the McCormick envelope approach [24]. Since the biogas delivery network is substantially limited by the CBP capacity, the network is usually designed as a radial structure (49) considering its shorter delivery distance and lower reliability requirement, which is in contrast to natural gas pipelines [25]-[27].

$$
\begin{aligned}
& \sum_{n_{s} \in \Omega_{n}} G F_{t b w n_{s} n}=G D_{t b w n}+\sum_{n_{t} \in \Omega_{n}} G F_{t b w n_{r}}-\sum_{n \in N B} B G_{t b w n} \\
& +\sum_{g \in \Omega_{n}} P G_{t b w g}, \forall n, n_{s}, n_{r} \in N P, \forall t, \forall b, \forall w \\
& x_{p t} G F^{\min } \leq G F_{t b w n_{s} n_{r}} \leq x_{p t} G F^{\max } \\
& \forall n_{s}, n_{r} \in N P, \forall t, \forall b, \forall w \\
& G P^{\min } \leq G P_{t b w n} \leq G P^{\max }, \forall n, \forall t, \forall b, \forall w \\
& G F_{t b w n_{s} n_{r}}=\operatorname{sgn}\left(G P_{t b w n_{s}}, G P_{t b w n_{r}}\right) \cdot K_{n_{s} n_{r}} \cdot \sqrt{\mid G P_{t b w n_{s}}^{2}-G P_{t b s n_{r}}^{2}} \\
& \forall n_{r}, n_{r} \in N P, \forall t, \forall b, \forall w \\
& \begin{aligned}
& \operatorname{sgn}\left(G P_{t b w n_{s}}, G P_{t b w n_{r}}\right)=\left\{\begin{aligned}
1, G P_{t^{\prime b w n_{s}}} & \geq G P_{t b w n_{r}} \\
-1, G P_{t b w n_{s}} & <G P_{t b s n_{r}}
\end{aligned}\right. \\
& \forall n, n \in N P, \forall t, \forall b, \forall w
\end{aligned} \\
& \left(\xi_{t b w n_{s} n_{r}}^{+}-\xi_{t b w n_{s} n_{r}}^{-}\right)\left(G P_{t b w n_{s}}-G P_{t b w n_{r}}\right)=1 / K_{n_{s} n_{r}}^{2} \cdot G F_{t b w n_{s} n_{r}}^{2} \\
& \forall n_{s}, n_{r} \in N P, \forall t, \forall b, \forall w \\
& -\left(1-\xi_{t b w n_{s} n_{r}}^{+}\right) \cdot G F^{\max } \leq G F_{t b w n_{s} n_{r}} \leq-\left(1-\xi_{t b w n_{s} n_{r}}^{-}\right) \cdot G F^{\max } \\
& \forall n_{s}, n_{r} \in N P, \forall t, \forall b, \forall w \\
& \xi_{t b w n_{s} n_{r}}^{+}+\xi_{t b w n_{s} n_{r}}^{-}=1, \forall n_{s}, n_{r} \in N P, \forall t, \forall b, \forall w \\
& \theta_{t b w n_{s} n_{r}} \geq 1 / K_{n_{s} n_{r}}^{2} \cdot G F_{t b w n_{s} n_{r}}^{2}, \forall n_{s}, n_{r} \in N P, \forall t, \forall b, \forall w \\
& \theta_{t b w n_{s} n_{r}} \geq\left(\xi_{t b w n_{s} n_{r}}^{+}-\xi_{t b w n_{s} n_{r}}^{-}+1\right)\left(G P^{\min }-G P^{\max }\right) \\
& +G P_{t b w n_{r}}-G P_{t b w n_{s}}, \forall n_{s}, n_{r} \in N P, \forall t, \forall b, \forall w \\
& \theta_{t b w n_{s} n_{r}} \geq\left(\xi_{t b w n_{s} n_{r}}^{+}-\xi_{t b w n_{s} n_{r}}^{-}-1\right)\left(G P^{\max }-G P^{\min }\right) \\
& +G P_{t b w n_{s}}-G P_{t b w n_{r}}, \forall n_{s}, n_{r} \in N P, \forall t, \forall b, \forall w \\
& \theta_{t b w n_{s} n_{r}} \leq\left(\xi_{t b w n_{s} n_{r}}^{+}-\xi_{t b w n_{s} n_{r}}^{-}+1\right)\left(G P^{\max }-G P^{\min }\right) \\
& +G P_{t b w n_{r}}-G P_{t b w n_{s}}, \forall n_{s}, n_{r} \in N P, \forall t, \forall b, \forall w \\
& \theta_{t b w n_{s} n_{r}} \leq\left(\xi_{t b w n_{s} n_{r}}^{+}-\xi_{t b w n_{s} n_{r}}^{-}-1\right)\left(G P^{\min }-G P^{\max }\right) \\
& +G P_{t b w n_{s}}-G P_{t b w n_{r}}, \forall n_{s}, n_{r} \in N P, \forall t, \forall b, \forall w \\
& \sum_{p \in N P} x_{p t}=N_{N N}^{t}-N_{S}-1, \forall t
\end{aligned}
$$

\section{4) Coupling Constraints}

The electric power network is coupled with the biogas delivery network through biogas-fired generators, given by (50).

$$
P G_{t b w g}=\alpha P E_{t b w g}+\beta, \forall t, b, w, g
$$

This model is formulated as a MISOCP problem using the objective (10) and subject to (1)-(9), (11)-(38), (42)-(50).

\section{Proposed Solution Method}

In this section, the proposed MISOCP problem is first converted into a tractable MILP problem by using the polyhedral approximation method. Then, the proposed twostage problem is reformulated as a multi-stage problem by adding non-anticipativity constraints to determine sequential investment variables upon the gradual uncertainty realization.

\section{A. Linearization}

Although a convex MISOCP problem can be directly solved by commercial solvers, it is still computationally demanding when a multistage problem involves more scenarios. To overcome the nonlinearities of (23), (24) and (44), they are rewritten in the following form of (51)-(53) as the first step.

$$
\begin{gathered}
S F_{t b w n_{s} n_{r}}^{a} \geq \sqrt{P F_{t b w n_{s} n_{r}}^{a^{2}}+Q F_{t b w n_{s} n_{r}}^{a^{2}}} \\
\left(I_{t b w n_{s} n_{r}}^{a}+V_{t b w n_{s}}\right) / 2 \geq \sqrt{\left[\left(I_{t b w n_{s} n_{r}}^{a}-V_{t b w n_{s}}\right) / 2\right]^{2}+S F_{t b w n_{s} n_{r}}^{a^{2}}} \\
\left(\theta_{t b w n_{s} n_{r}}+1\right) / 2 \geq \sqrt{\left[\left(\theta_{t b w n_{s} n_{r}}-1\right) / 2\right]^{2}+1 / K_{n_{s} n_{r}}^{2} \cdot G F_{t b w n_{s} n_{r}}^{2}}
\end{gathered}
$$

Correspondingly, (51)-(53) are represented as the secondorder conic constraints, which has a compact form as a secondorder conic constraint in (54).

$$
x_{3} \geq \sqrt{\left(x_{1}\right)^{2}+\left(x_{2}\right)^{2}}
$$

Constraint (54) is further approximated by a set of linear equalities and inequalities associated with a number of auxiliary variables $\varepsilon_{1}$ and $\eta_{1}$ in (55).

$$
\begin{aligned}
& \varepsilon_{\ell} \geq\left|x_{1}\right|, \eta_{\ell} \geq\left|x_{2}\right|, \ell=0 \\
& \varepsilon_{\ell}=\varepsilon_{\ell-1} \cos \left(\frac{\pi}{2^{\ell+1}}\right)+\eta_{\ell-1} \sin \left(\frac{\pi}{2^{\ell+1}}\right), \forall \ell \\
& \eta_{\ell} \geq\left|-\varepsilon_{\ell-1} \sin \left(\frac{\pi}{2^{\ell+1}}\right)+\eta_{\ell-1} \cos \left(\frac{\pi}{2^{\ell+1}}\right)\right|, \forall \ell \\
& \varepsilon_{\ell} \leq x_{3}, \eta_{\ell} \leq \varepsilon_{\ell} \tan \left(\frac{\pi}{2^{\ell+1}}\right), \ell=L
\end{aligned}
$$

Note that $L$ is a parameter that determines the number of additional constraints and variables when linearizing (54), and the linearization error will decrease as this parameter increases. The accuracy of this linearization technique is analyzed in [28].

Therefore, The general mathematical form for this proposed model is reformulated as a two-stage MILP in (56).

$$
\begin{array}{lr}
\min _{\left\{\boldsymbol{x}_{t}, \boldsymbol{y}_{w t}\right\}} & \sum_{t=1}^{T}\left[\boldsymbol{c}^{\Gamma} \boldsymbol{x}_{\boldsymbol{t}}+\sum_{w=1}^{W} P_{w} \cdot \boldsymbol{f}_{\boldsymbol{t}}\left(\boldsymbol{x}_{t}, \boldsymbol{y}_{w t}, \delta_{w}\right)\right] \\
\text { s.t. } & \boldsymbol{B}_{t} \boldsymbol{x}_{\boldsymbol{t}}+\boldsymbol{A} \boldsymbol{x}_{\boldsymbol{t}-1} \leq \boldsymbol{b}_{\boldsymbol{t}} \\
& \boldsymbol{E} \boldsymbol{y}_{w t}+\boldsymbol{F} \boldsymbol{x}_{\boldsymbol{t}} \leq \boldsymbol{h}_{w t}, \boldsymbol{x}_{\boldsymbol{t}} \in(1,0), \boldsymbol{y}_{w t} \geq 0
\end{array}
$$

where $\boldsymbol{x}_{\boldsymbol{t}}:=\left\{x_{1}, \ldots, x_{T}\right\}$ denotes the discrete investment variables; $\boldsymbol{y}_{w t}:=\left\{y_{w 1}, \ldots, y_{w T}\right\}$ denotes the continuous operational variables and $\delta_{w}$ represents the uncertainty realization for each scenario. 


\section{B. Multistage Stochastic Programming}

Since uncertainties cannot be all observed at the first stage, a more flexible multistage decision-making process is considered, as uncertainties are revealed. Accordingly, we approximate the uncertainty space by using a set of discrete scenarios. A scenario tree is constructed for representing variations in forecasting electric power and biogas loads and annual biomass availability. The root node represents loads and biomass availability at the first stage. In each subsequent stage, the load and biomass availability are increased in each scenario by assuming high, medium, low rates with their corresponding cumulative probability distributions, as shown in Table I. The seasonal load levels are represented in Table II by four load blocks, which are proportional to annual peak loads and considered using the historical data in [29]. Therefore, each scenario includes four load blocks and the annual biomass availability for all nodes in the networks.

Table I PROBABILITY FOR UNCERTAINTY STATES

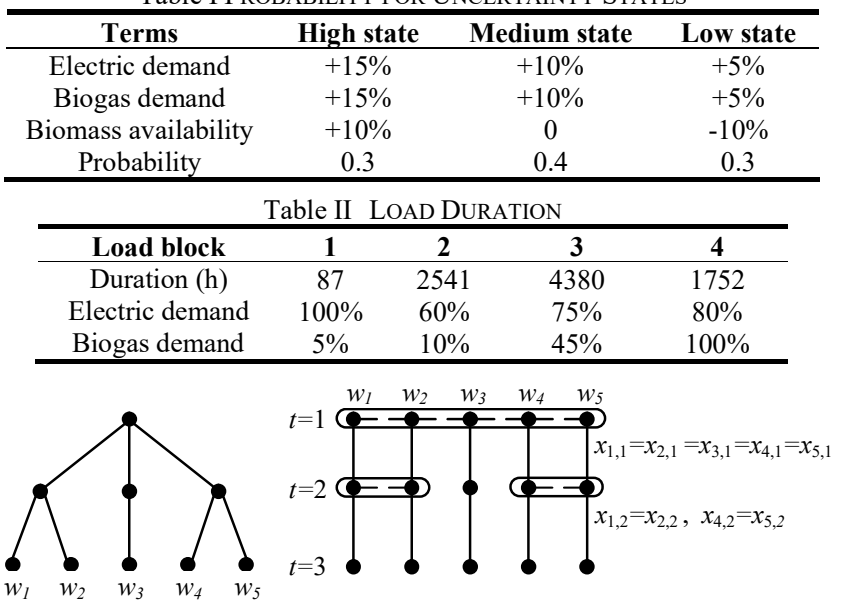

(a)

(b)

Fig. 2. Scenario generation (a) reduced scenario tree; (b) sequences of decisions and non-anticipativity.

To make this problem tractable, the scenario tree is reduced by applying GAMS SCENRED, as shown in Fig. 2(a). Following the reduced scenario tree in Fig. 2(a), each scenario at the leaf node has a unique sequence of uncertainty realization, represented by a sequence of branch arcs from the root to the leaves. Accordingly, the multistage problem is split into $W$ subproblems. We associate a set of flexible decisions in each scenario $\left\{\boldsymbol{x}_{w t}, \boldsymbol{y}_{w t}\right\}$ for discrete and continuous variables, which is formulated as:

$$
\begin{array}{lrl}
\min _{\left\{x_{w t}, y_{w t}\right\}} & \sum_{t=1}^{T} \sum_{w=1}^{W} P_{w}\left[\boldsymbol{c}^{\Gamma} \boldsymbol{x}_{w t}+\boldsymbol{f}_{t}\left(\boldsymbol{x}_{w t}, \boldsymbol{y}_{w t}, \delta_{w t}\right)\right] \\
\text { s.t. } & \boldsymbol{B}_{t} \boldsymbol{x}_{w t}+\boldsymbol{A} \boldsymbol{x}_{w t-1} \leq \boldsymbol{b}_{t} \\
& \boldsymbol{E} \boldsymbol{y}_{w t}+\boldsymbol{F} \boldsymbol{x}_{w t} \leq \boldsymbol{h}_{w t}, \boldsymbol{x}_{w t} \in(1,0), \boldsymbol{y}_{w t} \geq 0
\end{array}
$$

However, $\boldsymbol{x}_{\mathrm{wt}}$ is not be a random vector. The dependence of $\boldsymbol{x}_{\mathrm{wt}}$ on scenario may result from the observations carried out up to stage $t$. Therefore, non-anticipativity constraint is added to indicate that investment decisions corresponding to scenarios which are indistinguishable up to stage $t$ should be equal [30], as shown in Fig. 2(b). Thus, by enforcing non-anticipativity constraints, (57) can be recast as a T-stage problem with a finite number of scenarios in (58). Finally, the proposed model is formulated as a multistage MILP problem which is solved by GAMS.

$$
\begin{aligned}
& \min _{\left\{x_{w t}, y_{w t}\right\}} \quad \sum_{t=1}^{T} \sum_{w=1}^{W} P_{w}\left[\boldsymbol{c}^{\Gamma} \boldsymbol{x}_{w t}+\boldsymbol{f}_{t}\left(\boldsymbol{x}_{w t}, \boldsymbol{y}_{w t}, \delta_{w t}\right)\right] \\
& \text { s.t. } \quad \boldsymbol{B}_{t} \boldsymbol{x}_{w t}+\boldsymbol{A} \boldsymbol{x}_{w t-1} \leq \boldsymbol{b}_{\boldsymbol{t}} \\
& \boldsymbol{E}_{w t}+\boldsymbol{F} \boldsymbol{x}_{w t} \leq \boldsymbol{h}_{w t}, \boldsymbol{x}_{i t}=\boldsymbol{x}_{k t}, \boldsymbol{x}_{w t} \in(1,0), \boldsymbol{y}_{w t} \geq 0 \\
& \forall i, k \in\{1, \ldots, W\} \cap\left(\delta_{i 1}, \ldots, \delta_{i t-1}\right)=\left(\delta_{k 1}, \ldots, \delta_{k t-1}\right)
\end{aligned}
$$

\section{CASE StUdy}

\section{A. Initial Data}

The proposed methodology is verified using an 8-node system and a 24-node system for illustrating the effectiveness of the multistage expansion planning of integrated biogas and electric power delivery system considering the regional availability of biomass. The proposed model has been developed in GAMS and the Cplex solver is used. All tests are carried out on a PC with an Intel Core i7 CPU at $3.40 \mathrm{GHz}$ and 4GB of RAM.

A planning horizon of 15 years is adopted and subdivided into three stages. The interest rate is $10 \%$. The price of energy provided by the grid at the substation level is 57.7 US\$/MWh. The load power factor at each node is 0.95 lagging. The electric power network loss is priced at $10 \mathrm{US} \$ / \mathrm{MWh}$. The biogas production price is $130 \mathrm{US} \$ / \mathrm{km}^{3}$ [31], [32]. The variable and fixed feedstock transportation prices are 0.13 US\$ $/$ ton $-\mathrm{km}$ and 12 US\$/ton, respectively [33]. The spinning reserve requirement is $15 \%$ of the load at each block. Four typical load blocks represent seasonal load levels, which also indicate the seasonal correlations of electric and and biogas demands. Table I illustrates the uncertainty parameters for generating several scenarios discussed in Section. IV. Table II illustrates various loads in proportion to the corresponding peak demand at each block and their respective durations.

In order to illustrate the merits of the proposed model, five cases are demonstrated.

Case 1: The proposed multistage planning model incorporating biomass transportation network constraints is represented in (58). We solve (58) to obtain the optimal location of CBP.

Case 2: A two-stage stochastic planning without considering the biomass supply network. This model is solved in two steps: Step 1: The integrated electric power and biogas delivery network is first formulated as a MISOCP problem by (10)-(38), (42)-(50), regardless of terms associated with the biomass availability. The problem is solved by converting it into a MILP problem with the polyhedral approximation method. The solution provides the decisions for candidate lines $x_{l t}$, pipelines $x_{p t}$, generators $x_{g t}$ and the CBP location $x_{n}$.

Step 2: The values of $x_{n}, x_{p t}, x_{g t}, x_{l t}$ and scheduling variables in Step 1 are applied to (1)-(9) for minimizing the transportation cost which provides the optimal transportation routes. However, the solution results showed that there is no solution, which indicates that the Step 1 results cannot match the regional biomass availability; in other word, biomass demands in the Step 1 planning exceed the regional biomass supply capacity. 


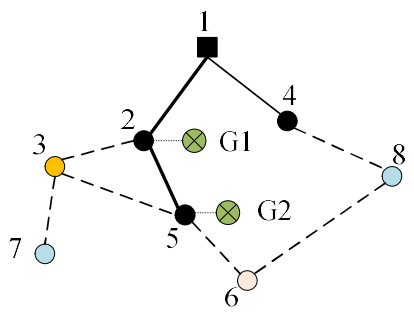

(a)

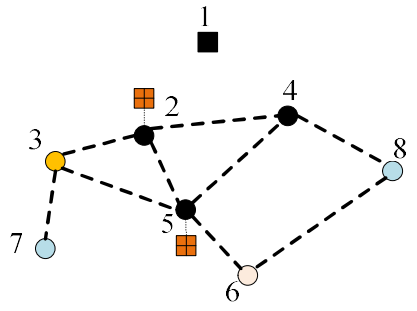

(b)

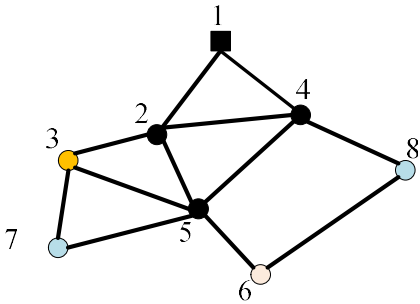

(c)

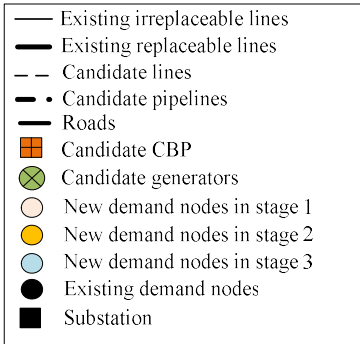

Fig. 3. Initial topology of 8-node system (a) electric network; (b) candidate biogas delivery network; (c) Biomass transportation network

Case 3: This case is a two-stage coordinated planning of coupling networks, which illustrates the advantages of multistage planning by comparing Cases 1 and 3 . The solution procedure in Case 3 is similar to that of Case 1 except no nonanticipativity constraint is added to Case 3 .

Case 4: This case is similar to Case 1. The difference is that the nodal biomass availability is varied as listed in Table III.

Case 5: This case is similar to Case 2. The difference is that the nodal biomass availability is varied as listed in Table III. Here, Case 4 is a multi-stage planning as Case 1 while Case 5 is a two-stage planning without considering the biomass transportation network.

\section{B. 8-Node System Case}

In Fig. 3, the topology of the 8-bus system, candidate biogas delivery and transportation network are shown. The optimality gap is $1 \%$. The base power of the system is $24.9 \mathrm{kV}$ and the upper power generation at the substation is 20 MVA. Nodal peak loads and annual biomass availability in the planning horizon are presented in Table III, which indicate how new loads are added over the planning horizon (Stage 1: Nodes 1-6; Stage 2: Node 3; Stage 3: Nodes 7 and 8). There are no loads or biomass at Node 1 where the substation is located. The biomass availability is represented in two groups. Table IV shows investment alternatives on conductors. Here, $a_{l}$ is the existing type of conductor in the network and $a_{2}$ is the second alternative for adding conductors. The data regarding lengths of lines, pipelines, and transportation routes are adapted from [34].

Table III 8-Node System-Peak Demand AND Biomass AVAILABILITY

\begin{tabular}{|c|c|c|c|c|c|}
\hline \multirow[t]{2}{*}{ Node } & & \multirow{2}{*}{$\begin{array}{c}\text { Electric } \\
\text { demand } \\
\text { (MVA) }\end{array}$} & \multirow{2}{*}{$\begin{array}{c}\text { Biogas } \\
\text { demand } \\
\left(\mathrm{km}^{3}\right)\end{array}$} & \multicolumn{2}{|c|}{$\begin{array}{l}\text { Biomass availability } \\
\text { (dry Ton) }\end{array}$} \\
\hline & & & & A & B \\
\hline \multirow{5}{*}{ Stage 1} & 1 & 0 & 0 & 0 & 0 \\
\hline & 2 & 4.05 & 2.84 & 10000 & 25000 \\
\hline & 4 & 0.78 & 0.55 & 15000 & 25000 \\
\hline & 5 & 1.14 & 0.80 & 30000 & 25000 \\
\hline & 6 & 0.32 & 0.24 & 30000 & 25000 \\
\hline Stage 2 & 3 & 3.05 & 2.14 & 25000 & 25000 \\
\hline \multirow{2}{*}{ Stage 3} & 7 & 1.22 & 0.48 & 15000 & 25000 \\
\hline & 8 & 1.68 & 1.18 & 15000 & 25000 \\
\hline
\end{tabular}

Table IV 8-NODE SYSTEM DATA FOR CANDIDATE CONDUCTORS

\begin{tabular}{|c|c|c|c|c|}
\hline $\begin{array}{l}\text { Alternatives } \\
\text { (a) }\end{array}$ & $\begin{array}{c}\text { Resistance } \\
(\Omega / \mathbf{k m})\end{array}$ & $\begin{array}{c}\text { Reactance } \\
(\Omega / \mathbf{k m})\end{array}$ & $\begin{array}{l}\text { Ampacity } \\
\text { (A) }\end{array}$ & $\begin{array}{c}\text { Cost } \\
(\mathrm{US} \$ / \mathbf{k m})\end{array}$ \\
\hline$a_{1}$ & 0.614 & 0.399 & 168 & 10000 \\
\hline$a_{2}$ & 0.307 & 0.380 & 314 & 20000 \\
\hline
\end{tabular}

In Table $\mathrm{V}$, the optimization results for the five cases are listed, where (1) refers to adding $a_{1}$ and (2) means adding $a_{2}$ type of conductor, and (R) means replacing an existing $a_{l}$ conductor with $a_{2}$. Comparing Cases 1 and 2, we note that the optimization of the transportation network model is infeasible in Case 2, which indicates that the biomass availability cannot meet the load demands in Case 2 (i.e., without considering the coupling of the biomass transportation and electric power networks). Cases 4 and 5 are compared to illustrate the influence of the nodal biomass availability on the planning results. When the biomass availability is identical and abundant at each node, the total cost in Case 4 is similar to that of Case 5 (i.e., coordinated planning may not be required). However, variations in nodal biomass availability will have an effect on the planning decisions. Additionally, the merits of multistage planning are further illustrated by comparing Cases 1 and 3 . The total cost of Case 1 is slightly lower than that of Case 3 because of the flexible decision making. Note that the optimal location of CBP varies in 5 proposed cases (i.e., Node 5 in Cases 1 and 4, and Node 2 in Cases 2, 3 and 5).

Table V 8-NODE SYSTEM COST COMPARISONS (M\$)

\begin{tabular}{cccccc}
\hline Case No. & $\mathbf{1}$ & $\mathbf{2}$ & $\mathbf{3}$ & $\mathbf{4}$ & $\mathbf{5}$ \\
Biomass availability & $\mathbf{A}$ & $\mathbf{A}$ & $\mathbf{A}$ & $\mathbf{B}$ & $\mathbf{B}$ \\
CBP location & Node 5 & Node 2 & Node 2 & Node 5 & Node 2 \\
Transportation cost & 4.10 & N/A & 4.23 & 4.46 & 4.54 \\
Investment cost & 1.34 & 1.14 & 1.25 & 1.20 & 1.14 \\
CBP Operation cost & 11.32 & 12.30 & 11.32 & 12.30 & 12.30 \\
Network losses cost & 3.84 & 0.006 & 3.87 & 0.018 & 0.006 \\
Total cost & 20.60 & N/A & 20.67 & 17.98 & 17.99 \\
\hline
\end{tabular}

Table VI 8-NODE SYSTEM PLANNING DECISIONS FOR DIFFERENT SCENARIOS

\begin{tabular}{|c|c|c|c|c|}
\hline \multicolumn{2}{|c|}{$\begin{array}{c}\text { Scenario } \\
\text { Probability }\end{array}$} & Stage 1 & Stage 2 & \multirow{2}{*}{\begin{tabular}{l}
\multicolumn{1}{c}{ Stage 3} \\
Lines: $3-7(1), 6-8$ \\
(1) \\
Pipes: $3-7,4-8$ \\
Generators: G3 \\
\end{tabular}} \\
\hline \multirow{5}{*}{$\begin{array}{c}\text { Case } \\
1\end{array}$} & $\begin{array}{l}\text { Scenario } 1 \\
(0.09)\end{array}$ & \multirow{5}{*}{$\begin{array}{l}\text { Lines: } 5-6 \\
\text { (1) } \\
\text { Pipes: } 2-4 \text {, } \\
\text { 2-5, 5-6 } \\
\text { Generator: } \\
\text { G2 }\end{array}$} & \multirow{2}{*}{$\begin{array}{l}\text { Lines: } 2-3 \\
\text { (1) } \\
\text { Pipes: } 3-5\end{array}$} & \\
\hline & $\begin{array}{c}\text { Scenario } 2 \\
(0.12)\end{array}$ & & & $\begin{array}{l}\text { Lines: } 3-7(1), 4-8 \\
\text { (1), 1-2(R), 1-4(R) } \\
\text { Pipes: } 3-7,4-8\end{array}$ \\
\hline & $\begin{array}{c}\text { Scenario } 3 \\
(0.58)\end{array}$ & & $\begin{array}{l}\text { Lines: } 2-3 \\
(1), 1-2(\mathrm{R}) \\
\text { Pipes: } 3-5\end{array}$ & $\begin{array}{l}\text { Lines: } 4-8(1), 3-7 \\
(2) \\
\text { Pipes: } 3-7,4-8\end{array}$ \\
\hline & $\begin{array}{l}\text { Scenario } 4 \\
(0.12)\end{array}$ & & \multirow{2}{*}{$\begin{array}{l}\text { Lines: } 2-3 \\
\text { (2), 1-2(R) } \\
\text { Pipes: } 3-5 \\
\text { Generators: } \\
\text { G1 }\end{array}$} & $\begin{array}{l}\text { Lines: } 3-7(2), 4-8 \\
\text { (1) } \\
\text { Pipes: } 3-7,4-8\end{array}$ \\
\hline & $\begin{array}{c}\text { Scenario } 5 \\
(0.09)\end{array}$ & & & $\begin{array}{l}\text { Lines: 4-8(1), 1-2 } \\
\text { (R), 3-7(2) } \\
\text { Pipes: } 3-7,4-8\end{array}$ \\
\hline & Case 2 & $\begin{array}{l}\text { Lines: } 5- \\
6(1), \\
\text { Pipes: } 2-3 \text {, } \\
\text { 2-4, 4-5 } \\
\text { Generators: } \\
\text { G1, G2 }\end{array}$ & $\begin{array}{l}\text { Lines: } 2-3 \\
\text { (1) } \\
\text { Pipes: } 2-3\end{array}$ & $\begin{array}{l}\text { Lines: } 6-8(1), 3-7 \\
\text { (1) } \\
\text { Pipes: } 3-7,4-8\end{array}$ \\
\hline & Case 3 & $\begin{array}{l}\text { Lines: } 5- \\
\text { 6(1), 1-2(R) } \\
\text { Pipes: } 2-3, \\
\text { 2-4, 4-5 } \\
\text { Generators: } \\
\text { G1, G2 }\end{array}$ & $\begin{array}{l}\text { Lines: } 2-3 \\
\text { (2) } \\
\text { Pipes: } 2-3\end{array}$ & $\begin{array}{l}\text { Lines: } 4-8(1), 3-7 \\
\text { (1) } \\
\text { Pipes: } 3-7,4-8\end{array}$ \\
\hline
\end{tabular}



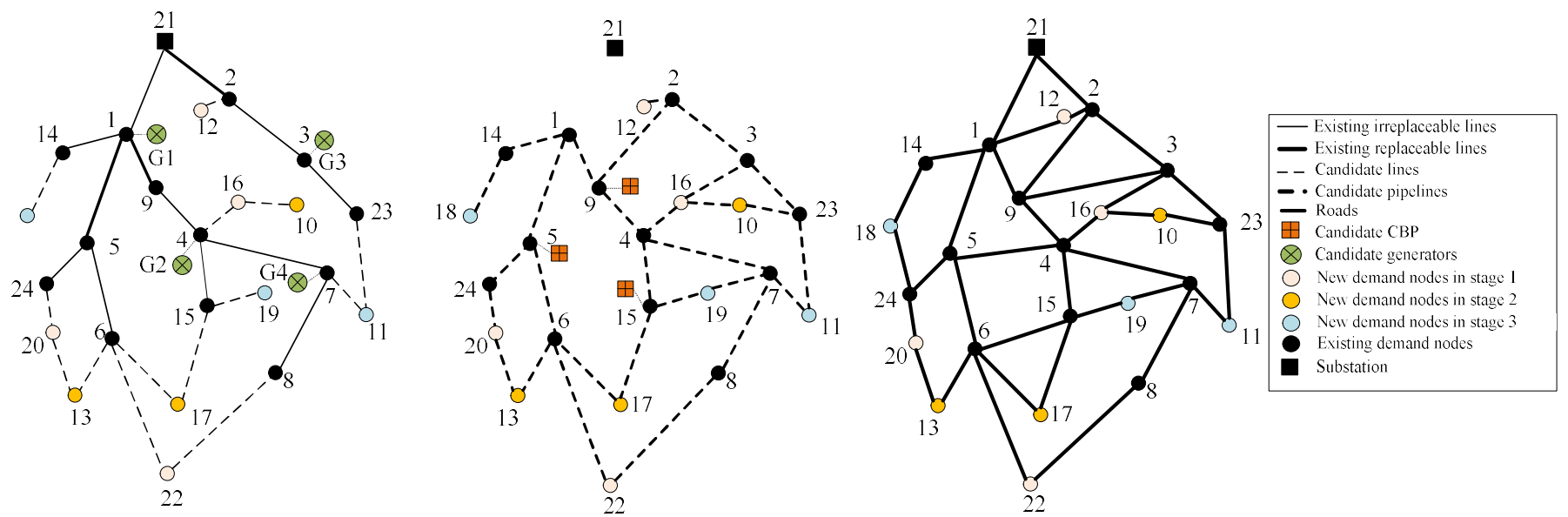

Fig. 4. Initial topology of a 24-node system (a) electric power network; (b) candidate biogas delivery network; (c) Biomass transportation network

\begin{tabular}{cccccc}
\multicolumn{6}{c}{ Table VII 24-NODE SYSTEM-COST COMPARISONS $(\mathrm{M} \$)$} \\
\hline Case No. & $\mathbf{1}$ & $\mathbf{2}$ & $\mathbf{3}$ & $\mathbf{4}$ & $\mathbf{5}$ \\
\hline CBP location & Node & Node & Node & Node & Node \\
Transportation cost & 9 & 5 & 9 & 15 & 5 \\
Investment cost & 4.26 & N/A & 18.26 & 18.43 & 19.10 \\
CBP Operation cost & 44.27 & 4.33 & 4.63 & 4.29 & 4.31 \\
Network losses cost & 7.40 & 0.26 & 44.27 & 46.09 & 46.09 \\
Total cost & 74.48 & N/A & 74.57 & 0.28 & 0.25 \\
\hline
\end{tabular}

Table VIII 24-Node System - PlanNing DeCisions FOR DifFERENT SCENARIOS

\begin{tabular}{|c|c|c|c|c|}
\hline \multicolumn{2}{|c|}{ Scenario } & Stage 1 & Stage 2 & Stage 3 \\
\hline \multirow{3}{*}{$\begin{array}{c}\text { Case } \\
1\end{array}$} & $\# 1$ & \multirow{3}{*}{$\begin{array}{l}\text { Lines: 4-16(1), 6- } \\
\text { 22(1), 20-24(1), 2- } \\
\text { 12(2) } \\
\text { Pipes: 1-5, 1-9, 4-7, 4- } \\
\text { 9, 5-6, 7-8, 2-9, 1-14, } \\
\text { 2-12, 3-16, 4-15, 4-16, } \\
\text { 5-24, 3-23, 20-24, 8-22 } \\
\text { Generators: G1, G2, } \\
\text { G3 }\end{array}$} & $\begin{array}{l}\text { Lines: } 1-5(\mathrm{R}), \\
\text { 10-16(1), } \\
13-20(1), \\
\text { 15-17(1) } \\
\text { Pipes: 6-13,10- } \\
\text { 16, 6-17 } \\
\text { Generators: G4 }\end{array}$ & $\begin{array}{l}\text { Lines: } 7-11 \\
(1), 14-18(1) \text {, } \\
\text { 15-19(1) } \\
\text { Pipes: } 7-11,7- \\
19,14-18\end{array}$ \\
\hline & $\# 2$ & & $\begin{array}{l}\text { Lines: 1-5(R), } \\
\text { 10-16(2), 13- } \\
20(1), 15-17 \\
(1) \\
\text { Pipes: 6-13,10- } \\
\text { 16,6-17 }\end{array}$ & $\begin{array}{l}\text { Lines: } 14-18 \\
(1), 15-19 \\
(1), 11-23(1) \\
\text { Pipes: } 7-11,7- \\
19,14-18\end{array}$ \\
\hline & $\# 3$ & & $\begin{array}{l}\text { Lines: 1-5(R), } \\
\text { 10-16(2), 13- } \\
20(1), 15-17 \\
\text { (1) } \\
\text { Pipes: 6-13,10- } \\
\text { 16,6-17 }\end{array}$ & $\begin{array}{l}\text { Lines: 7- } \\
\text { 11(1), 14-18 } \\
\text { (1), 15-19 (1) } \\
\text { Pipes: 7-11,7- } \\
\text { 19,14-18 } \\
\text { Generator: } \\
\text { G4 }\end{array}$ \\
\hline \multicolumn{2}{|c|}{ Case 2} & $\begin{array}{l}\text { Lines: 2-12(1), 4-16 } \\
\text { (1), 8-22(1), 20-24(1) } \\
\text { Pipes: 1-5, 1-9, 4-7, 4- } \\
9,5-6,7-8,2-9,1-14, \\
\text { 2-12, 3-16, 4-15, 4-16, } \\
\text { 8-22, 20-24, 5-24, 3-23 } \\
\text { Generators: G1. G3, } \\
\text { G4 }\end{array}$ & $\begin{array}{l}\text { Lines: } 2-3,10- \\
\text { 16(1), 15-17 } \\
\text { (1), 13-20(2) } \\
\text { Pipes: 6-13, } \\
\text { 10-16,15-17 } \\
\text { Generator: G2 }\end{array}$ & $\begin{array}{l}\text { Lines: 7- } \\
\text { 11(1), 14- } \\
\text { 18(1), 15- } \\
\text { 19(1) } \\
\text { Pipes: 7-11, } \\
\text { 14-18, 15-19 }\end{array}$ \\
\hline \multicolumn{2}{|c|}{ Case 3} & $\begin{array}{l}\text { Lines:2-12(1),4- } \\
\text { 16(1),20-24(1),6-22(2) } \\
\text { Pipes: 1-5,1-9,4-7,4- } \\
9,5-6,7-8,2-9,1-14,2- \\
12,3-16,4-15,4-16,5- \\
\text { 24,3-23,20-24,8-22 } \\
\text { Generators: G1, G2, } \\
\text { G3 }\end{array}$ & $\begin{array}{l}\text { Lines:10- } \\
\text { 16(1),13-20 } \\
(1), 15-17(1), 1- \\
\text { 5(R) } \\
\text { Pipes: 6-13,10- } \\
\text { 16,6-17 } \\
\text { Generators: G4 }\end{array}$ & $\begin{array}{l}\text { Lines: } 14-18 \\
\text { (1),15-19(1) } \\
\text { Pipes: } 7-11,7- \\
\text { 19,14-18 }\end{array}$ \\
\hline
\end{tabular}

The planning schemes in Cases 1-3 are given in Table VI, where scenario probabilities in Case 1 are included in parenthesis. The final decision is listed at Stage 3, where the multistage decision will substantially influence the final solution. The final pipeline investment decision is the same in three cases unless the CBP is located at different nodes. That is because the radial structure of the biogas delivery network is implicitly decided once the CBP location is determined.

\section{24-Node System Case}

Considering the biogas delivery network is a local energy supply network, a 24-node modified power distribution system is presented in Fig. 4 to illustrate the scalability of the proposed methodology. The optimality gap of this case is $5 \%$ and the execution time is around 8 hours. The electric power network is supplied by a 50 MVA substation with a base voltage at 24.9 $\mathrm{kV}$. It consists of 3 replaceable lines, 13 candidate lines, 28 candidate pipelines, 3 candidate CBP locations and 4 candidate biogas-fired generators. The scenario probabilities are $21 \%, 58 \%$ and $21 \%$, respectively. The planning results are presented in Tables VII and VIII, resulting in a similar conclusion to that of the 8-node system case. They both verify that the proposed planning model provides a tradeoff between the regional biomass availability and load demands, which will reduce the total cost and substantially influence the choice of CBP location and planning scheme.

\section{CONCLUSION}

In remote areas, the integration of CBP and electric power distribution network offers an affordable solution for regional energy services. Considering the coupling among electric power, biogas delivery and biomass transportation networks, a multistage integrated expansion planning model is proposed to overcome the challenges of possible insufficient biomass availability. The proposed model addresses the biomass transportation network and the impact of biomass availability on the CBP location selection as well as the annual planning scheme. The proposed model is reformulated from a MISOCP problem to a MILP problem by applying the polyhedral approximation to make it more tractable when the problem scales up. Besides, considering the ever-changing demand growth and biomass availability, multi-stage investment 
decisions are made upon the gradual uncertainties revealed by adding the non-anticipativity constraints, which can slightly reduce the total cost and influence the CBP allocation and the planning scheme. As a renewable energy, biogas will be a promising solution to energy access in remote areas. The proposed model is an interdisciplinary study for combining the power system and bioenergy, which can inspire the further applications of bioenergy in power systems.

\section{REFERENCES}

[1] B. Zhao, A. J. Conejo and R. Sioshansi, "Coordinated Expansion Planning of Natural Gas and Electric Power Systems," IEEE Trans. Power Syst., vol. 33, no. 3, pp. 3064-3075, May 2018.

[2] B. Odetayo, M. Kazemi, J. MacCormack, W. D. Rosehart, H. Zareipour and A. R. Seifi, "A Chance Constrained Programming Approach to the Integrated Planning of Electric Power Generation, Natural Gas Network and Storage," IEEE Trans. Power Syst., vol. 33, no. 6, pp. 6883-6893, Nov. 2018.

[3] T. Ding, Y. Hu and Z. Bie, "Multi-Stage Stochastic Programming with Nonanticipativity Constraints for Expansion of Combined Power and Natural Gas Systems," IEEE Trans. Power Syst., vol. 33, no. 1, pp. 317328, Jan. 2018.

[4] C. He, L. Wu, T. Liu and Z. Bie, "Robust Co-Optimization Planning of Interdependent Electricity and Natural Gas Systems with a Joint N-1 and Probabilistic Reliability Criterion," IEEE Trans. Power Syst., vol. 33, no. 2, pp. 2140-2154, Mar. 2018.

[5] C. Shao, M. Shahidehpour, X. Wang, X. Wang and B. Wang, "Integrated Planning of Electricity and Natural Gas Transportation Systems for Enhancing the Power Grid Resilience," IEEE Trans. Power Syst., vol. 32, no. 6, pp. 4418-4429, Nov. 2017.

[6] J. Qiu, Z. Y. Dong, J. H. Zhao, K. Meng, Y. Zheng and D. J. Hill, "Low Carbon Oriented Expansion Planning of Integrated Gas and Power Systems," IEEE Trans. Power Syst., vol. 30, no. 2, pp. 1035-1046, Mar. 2015.

[7] Y. Hu, Z. Bie, T. Ding and Y. Lin, “An NSGA-II Based Multi-objective Optimization for Combined Gas and Electricity Network Expansion Planning", Appl. Energy, vol. 167, pp. 280-293, April 2016.

[8] A. Saldarriaga, R. A. Hincapi'e, and H. Salazar, "A Holistic Approach for Planning Natural Gas and Electricity Distribution Networks," IEEE Trans. Power Syst., vol. 28, no. 4, pp. 4052-4063, Nov. 2013

[9] A. Picardo, V.M. Soltero, M.E. Peralta, and R. Chacartegui, "District Heating Based on Biogas from Wastewater Treatment Plant," Energy, vol. 180, pp. 649-664, Aug. 2019.

[10] A. Akgül, and S.U. Seçkiner, "Optimization of Biomass to Bioenergy Supply Chain with Tri-Generation and District Heating and Cooling Network Systems," Computers \& Industrial Engineering, vol. 137, pp. 106017, Nov. 2019.

[11] A. M. Pantaleo, S. Giarola, A. Bauen and N. Shah, "Integration of Biomass into Urban Energy Systems for Heat and Power. Part I: An MILP based spatial optimization methodology," Energy Conversion and Management, vol. 83, pp. 347-361, July 2014.

[12] V. Vukašinović, and D. Gordić, "Optimization and GIS-based Combined Approach for the Determination of the Most Cost-effective Investments in Biomass Sector," Applied energy, vol.178, pp.250-259, Sep. 2016.

[13] J. Höhn, E. Lehtonen, S. Rasi, and J. Rintala, "A Geographical Information System (GIS) based Methodology for Determination of Potential Biomasses and Sites for Biogas Plants in Southern Finland," Appl. Energy, vol.113, pp.1-10, Jan. 2014.

[14] K. T. Malladi and T. Sowlati, "Biomass logistics: A Review of Important Features, Optimization Modeling and the New Trends," Renewable and Sustainable Energy Reviews, vol. 94, pp.587-599, Oct. 2018.

[15] S. Lei, J. Wang, C. Chen and Y. Hou, "Mobile Emergency Generator Pre-Positioning and Real-Time Allocation for Resilient Response to Natural Disasters," IEEE Trans. Smart Grid, vol. 9, no. 3, pp. 2030-2041, May 2018.

[16] Q. Zhou, Z. Tian, M. Shahidehpour, X. Liu, A. Alabdulwahab and A. Abusorrah, "Optimal Consensus-Based Distributed Control Strategy for Coordinated Operation of Networked Microgrids," IEEE Trans. Power Syst., vol. 35, no. 3, pp. 2452-2462, May 2020

[17] Q. Zhou, M. Shahidehpour, A. Paaso, S. Bahramirad, A. Abdulwhab, and A. M. Abusorrah, "Distributed Control and Communication Strategies in Networked Microgrids," IEEE Communications Surveys \& Tutorials, early access, 2020 [online]. Available: doi: 10.1109/COMST.2020.3023963

[18] N. C. Koutsoukis, P. S. Georgilakis and N. D. Hatziargyriou, "Multistage Coordinated Planning of Active Distribution Networks," IEEE Trans. Power Syst., vol. 33, no. 1, pp. 32-44, Jan. 2018.

[19] A. Zare, C. Y. Chung, J. Zhan and S. O. Faried, "A Distributionally Robust Chance-Constrained MILP Model for Multistage Distribution System Planning with Uncertain Renewables and Loads," IEEE Trans. Power Syst., vol. 33, no. 5, pp. 5248-5262, Sept. 2018.

[20] Q. Chen, X. Zhao and D. Gan, "Active-reactive Scheduling of Active Distribution System Considering Interactive Load and Battery Storage," Protection and Control of Modern Power Systems, vol.2, no. 1, pp. 320330, Dec. 2017.

[21] M. Farivar and S. H. Low, "Branch Flow Model: Relaxations and Convexification," Proc. IEEE 51 $1^{\text {st }}$ Annu. Conf. Decision Control, Dec. 2012, pp. 3672-3679.

[22] M. Lavorato, J. F. Franco, M. J. Rider and R. Romero, "Imposing Radiality Constraints in Distribution System Optimization Problems," IEEE Trans. Power Syst., vol. 27, no. 1, pp. 172-180, Feb. 2012.

[23] P. Liu, T. Ding, Z. Zou, Y. Yang, "Integrated Demand Response for a Load Serving Entity in Multi-energy Market Considering Network Constraints," Applied Energy, vol.250, pp. 512-529, Sep. 2019,

[24] C. Borraz-Sánchez, R. Bent, S. Backhaus, H. Hijazi, and P.V. Hentenryck, "Convex Relaxations for Gas Expansion Planning," Journal on Computing, vol. 28, no. 4, pp. 645-656, Aug. 2016.

[25] X. Zhang, M. Shahidehpour, A. Alabdulwahab and A. Abusorrah, "Hourly Electricity Demand Response in the Stochastic Day-Ahead Scheduling of Coordinated Electricity and Natural Gas Networks," IEEE Trans. Power Syst., vol. 31, no. 1, pp. 592-601, Jan. 2016.

[26] C. He, L. Wu, T. Liu and M. Shahidehpour, "Robust Co-Optimization Scheduling of Electricity and Natural Gas Systems via ADMM," IEEE Trans. Sustain. Energy., vol. 8, no. 2, pp. 658-670, April 2017.

[27] W. Jia, T. Ding, C. Huang, Z. Wang, Q. Zhou and M. Shahidehpour, "Convex Optimization of Integrated Power-Gas Energy Flow Model and Application to Probabilistic Energy Flow," IEEE Trans. Power Syst., early access [online]. Available: $d$ oi: 10.1109/TPWRS.2020.3018869.

[28] A. Ben-Tal, and A. Nemirovski, "On Polyhedral Approximations of the Second-order Cone," Mathematics of Operations Research, vol.26, no. 2, pp. 193-205, May. 2001.

[29] Office of Energy Efficiency \& Renewable Energy (EERE), Commercial and Residential Hourly Load Profiles for all TMY3 Locations in the United States, Jul. 2013 [Online]. Available: https://openei.org/doeopendata/dataset/commercial-and-residential-hourly-load-profiles-forall-tmy3-locations-in-the-united-states

[30] C. H. Rosa and A. Ruszczyński, "On Augmented Lagrangian Decomposition Methods for Multistage Stochastic Programs," Annals of Operations Research, vol. 64, no. 1, pp. 289-309, Dec. 1996.

[31] J. Gan and C.T. Smith, "Optimal Plant Size and Feedstock Supply Radius: A Modeling Approach to Minimize Bioenergy Production Costs," Biomass and Bioenergy, vol. 35, no. 8, pp. 3350-3359, Aug. 2011.

[32] International Energy Agency, "Outlook for Biogas and Biomethane: Prospects for Organic Growth", IEA, Paris, France, Mar. 2020. [Online]. Available: $\quad$ https://www.iea.org/reports/outlook-for-biogas-andbiomethane-prospects-for-organic-growth

[33] P. Maheshwari, S. Singla, and Y. Shastri, "Resiliency Optimization of Biomass to Biofuel Supply Chain Incorporating Regional Biomass Preprocessing Depots," Biomass and bioenergy, vol. 97, pp. 116-131, Feb. 2017.

[34] A. Tabares, J. F. Franco, M. Lavorato and M. J. Rider, "Multistage LongTerm Expansion Planning of Electrical Distribution Systems Considering Multiple Alternatives," IEEE Trans. Power Syst., vol. 31, no. 3, pp. 1900-1914, May 2016.

\section{BIOGRAPHIES}

Hanyu Yang (S'20) received the B.E. degree from the College of Electrical Engineering in Hunan University, Changsha, China, in 2015. She is currently pursuing the Ph.D. degree in electrical engineering from Hunan University, Changsha, China. She was a visiting student at Robert W. Galvin Center for Electricity Innovation at Illinois Institute of Technology. Her research interests include power system planning and integrated energy system

Canbing Li (M'06-SM'13) received the B.E. and Ph.D. degree from Tsinghua University, Beijing, China, in 2001 and 2006, respectively, both in electrical 
engineering. He is currently a professor with the School of Electronic Information and Electrical Engineering, Shanghai Jiao Tong University. His research interests include power systems, smart grid, renewable energy, with an emphasis on large-scale power system dispatch, economic and secure operation of power systems, energy efficiency and energy saving in smart grid, electric demand management of data centers, vehicle-to-grid technologies.

Mohammad Shahidehpour ( $\mathrm{F}^{\prime} 01$ ) received an Honorary Doctorate degree from the Polytechnic University of Bucharest, Bucharest, Romania. He is a University Distinguished Professor, Bodine Chair Professor, and Director of the

Robert W. Galvin Center for Electricity Innovation at Illinois Institute of Technology. He is a Fellow of IEEE, the American Association for the Advancement of Science (AAAS), and the National Academy of Inventors (NAI). Dr. Shahidehpour is a member of the US National Academy of Engineering.

Cong Zhang (S'15) received the B.S. degree and the Ph.D degree in South China University of Technology, Guangzhou, China, in 2013 and 2018, respectively. He is currently an Assistant Professor with the School of Electrical and Information Engineering, Hunan University, Changsha, China. His current research interest is reactive power optimization incorporating uncertainties and interval.

Bin Zhou (S'11-M'13-SM'17) received the B.E. degree in electrical engineering from Zhengzhou University, Zhengzhou, China, in 2006, the M.E. degree in electrical engineering from South China University of Technology, Guangzhou, China, in 2009, and the Ph.D. degree from Hong Kong Polytechnic University, Hong Kong, in 2013. Now, he is an Associate Professor in the College of Electrical and Information Engineering, Hunan University, Changsha, China. His main fields of research include smart grid operation and planning, renewable energy generation, and energy efficiency.

Qiuwei Wu (M'08-SM'15) recieved the $\mathrm{PhD}$ degree in Power System Engineering from Nanyang Technological University, Singapore, in 2009. He has been working at Department of Electrical Engineering, Technical University of Denmark (DTU) since 2009. His research interests are operation and control of power systems with high penetration of renewables, including wind power modelling and control, active distribution networks, and operation of integrated energy systems. 